\title{
New-onset kidney biopsy-proven IgA vasculitis after receiving mRNA-1273 COVID-19 vaccine: case report
}

\author{
Shinya Nakatani ${ }^{1} \oplus \cdot$ Katsuhito Mori $^{2} \cdot$ Fumiyuki Morioka $^{1} \cdot$ Chika Hirata $^{3} \cdot$ Akihiro Tsuda $^{1} \cdot$ Hideki Uedono $^{1}$. \\ Eiji Ishimura ${ }^{4} \cdot$ Daisuke Tsuruta $^{3} \cdot$ Masanori Emoto $^{1,2}$
}

Received: 5 November 2021 / Accepted: 15 December 2021 / Published online: 25 January 2022

(c) Japanese Society of Nephrology 2021

\begin{abstract}
As mRNA COVID-19 vaccines have become widely available, cases of new-onset glomerular disease after receiving COVID19 vaccination have been reported. Here, we present a case of kidney biopsy-proven new-onset IgA vasculitis after receiving the mRNA-1273 (Moderna) COVID-19 vaccination. A 47-year-old man with a 10-year medical history of hypertension and hyperuricemia visited our hospital 19 days after receiving an initial mRNA-1273 COVID-19 vaccine injection for purpuric eruption on the legs and dorsal regions of the feet. Although the eruptions spontaneously improved within 5 days, they developed again at 15 days after the second injection. A histopathological examination of skin biopsy specimens was reminiscent of leukocytoclastic vasculitis, though direct immunofluorescence did not indicate IgA deposition within small vessel walls. Urinalysis indicated severe proteinuria $(3+)$ and occult blood $(3+)$. Thus, a kidney biopsy was performed and light microscopy revealed mild mesangial expansion, hypercellularity, and endocapillary hypercellularity, with cellular and fibrocellular crescents observed in three and one, respectively, of a total of 15 glomeruli. Immunofluorescence also showed diffuse granular mesangial staining $(3+)$ for IgA. Histopathological features were consistent with IgA vasculitis. Intravenous methylprednisolone at $1000 \mathrm{mg}$ for 3 days was initiated, followed by oral prednisolone $(0.6 \mathrm{mg} / \mathrm{kg} / \mathrm{day})$. Over the following 2-week period, serum creatinine level improved from 1.24 to $1.06 \mathrm{mg} / \mathrm{dL}$ and proteinuria decreased from 2.98 to $0.36 \mathrm{~g} / \mathrm{g}$ $\mathrm{Cr}$, though occult blood persisted. Findings in the present case indicate that new-onset IgA vasculitis after receiving mRNA1273 COVID-19 vaccine can be treated with corticosteroid therapy.
\end{abstract}

Keywords mRNA-1273 COVID-19 vaccine $\cdot$ IgA vasculitis $\cdot$ Vaccination

\section{Introduction}

Coronavirus disease 2019 (COVID-19) is caused by infection with the severe acute respiratory syndrome coronavirus 2 (SARS-CoV-2) strain of virus. The first cluster of

Shinya Nakatani

m2026719@med.osaka-cu.ac.jp

1 Department of Metabolism, Endocrinology and Molecular Medicine, Osaka City University Graduate School of Medicine, 1-4-3 Asahi-machi, Abeno-ku, Osaka 545-8585, Japan

2 Department of Nephrology, Osaka City University Graduate School of Medicine, Osaka, Japan

3 Department of Dermatology, Osaka City University Graduate School of Medicine, Osaka, Japan

4 Department of Nephrology, Meijibashi Hospital, Matsubara, Japan
COVID-19 cases in individuals associated with the Huanan Seafood Wholesale Market in Wuhan, Hubei Province, China, was reported on December 31, 2019 (https://www. who.int/csr/don/05-january-2020-pneumonia-of-unkowncause-china/en/), then following the worldwide spread of COVID-19, a pandemic was declared by the World Health Organization on March 11, 2020 (https://www.who.int/dg/ speeches/detail/who-director-general-s-opening-remarksat-the-media-briefing-on-covid-19-11-march-2020). As of October 11, 2021, this emerging highly infectious disease had spread to $237,383,711$ individuals throughout the world, with 4,842,716 related deaths reported (https://www.who. int/emergencies/diseases/novel-coronavirus-2019) [00:52 am CET, October 12, 2021].

To improve the COVID-19 pandemic situation, two different mRNA vaccines, BNT162b2 mRNA COVID-19 (Pfizer-BioNTech) and mRNA-1273 COVID-19 (Moderna), were authorized by the US Food and Drug Administration 
on December 11, 2020 and December 18, 2020, respectively. Along with increasing wide availability of those vaccines, cases of vaccine-related new-onset glomerular diseases, including minimal change disease (MCD) [1-5], anti-neutrophil cytoplasmic autoantibody (ANCA)-associated vasculitis $[6,7]$, and immunoglobulin A ( $\operatorname{IgA})$ nephropathy [8], that developed after receiving the BNT162b2 mRNA COVID-19 vaccine have been reported. Furthermore, cases of MCD [9], ANCA-associated vasculitis $[10,11]$, and IgA nephropathy [11-13] have also been reported in individuals who received the mRNA-1273 COVID-19 vaccine.

IgA vasculitis, also referred to as Henoch-Schoenlein purpura, is characterized by immunoglobulin A1 (IgA1)dominant immune deposits that affect small vessels and often involves the skin, gastrointestinal tract, joints, and kidneys [14], with approximately $40-50 \%$ of these cases known to develop simultaneous hematuria and proteinuria [15]. Previous studies have noted occurrence of IgA vasculitis following vaccinations for influenza [16] and hepatitis A [17]. New-onset IgA vasculitis after receiving the BNT162b2 mRNA COVID-19 vaccine has also been reported [18, 19], in which kidney function and urinalysis were normal, as well as a case of new onset IgA vasculitis in an individual who received the mRNA-1273 COVID-19 vaccine [13]. However, a kidney biopsy was not performed for any of those latter three patients, thus no renal histopathological information regarding new-onset IgA vasculitis with kidney involvement after receiving the mRNA COVID-19 vaccine has been made available. Here, we present the first case of kidney biopsy-proven new-onset IgA vasculitis following vaccination with the mRNA-1273 COVID-19 vaccine.

\section{Case report}

We treated a 47-year-old male for purpuric eruptions on the legs and dorsal regions of the feet after receiving mRNA1273 COVID-19 vaccine injections. The patient had a ten-year history of hypertension, for which he was given azilsartan (40 mg) and amlodipine (5 mg), and also of hyperuricemia, with febuxostat $(10 \mathrm{mg})$ prescribed. At the time of onset of hypertension, there was no urinary abnormality. There was no known history of kidney disease including glomerulopathies in the patient or his family members. A purpuric eruption developed on the legs and dorsal regions of the feet 19 days after receiving the first mRNA-1273 COVID-19 vaccination injection, which spontaneously improved at 24 days after receiving that. As scheduled, the second injection was received at 28 days after the first.

Fifteen days following the second vaccination, the patient was referred to the Department of Dermatology of Osaka City University Hospital, and clinical findings showed palpable purpuric papules on the legs and dorsa of the feet (Fig. 1a). On day 16 after the second vaccination, a skin biopsy was performed and histopathological results showed perivascular dermatitis with mixed inflammation, including lymphocytes, neutrophils, and related nuclear dust. Erythrocyte extravasation was also observed in the dermis (Fig. 1b). Although gross hematuria was not noted, urinalysis results showed severe proteinuria $(3+)$ and occult blood $(3+)$. The patient was then admitted to the Department of Nephrology at Osaka City University Hospital on day 28.

Upon admission, body temperature was $36.7{ }^{\circ} \mathrm{C}$ and blood pressure was $118 / 72 \mathrm{mmHg}$. Physical examination findings of the heart, lungs, abdomen, and nervous system were unremarkable. There was no pitting edema or palpable purpura on the legs or feet dorsal regions. The previously noted eruptions were reported to have spontaneously and completely diminished at 20 days after the second vaccination. Table 1 shows laboratory and urinary data at the time of admission. Urinalysis results presented severe proteinuria $(3+)$ and occult blood $(3+)$, and a spot urine protein/creatine ratio of $2.98 \mathrm{~g} / \mathrm{g}$ Cr. Moreover, urinary analysis of sediment revealed 50-99 red blood cells per high power field $(\times 400)$. These results were obviously worse as compared to those obtained at seven days before the first vaccination at his most recent
Fig. 1 Skin findings. a Palpable purpuric papules were observed on the legs and dorsal regions of the feet on day 15 after the second vaccination. b Skin biopsy results showed a mixture of perivascular inflammation and erythrocyte extravasation in the dermis [hematoxylin and eosin, $\times 200$ ]
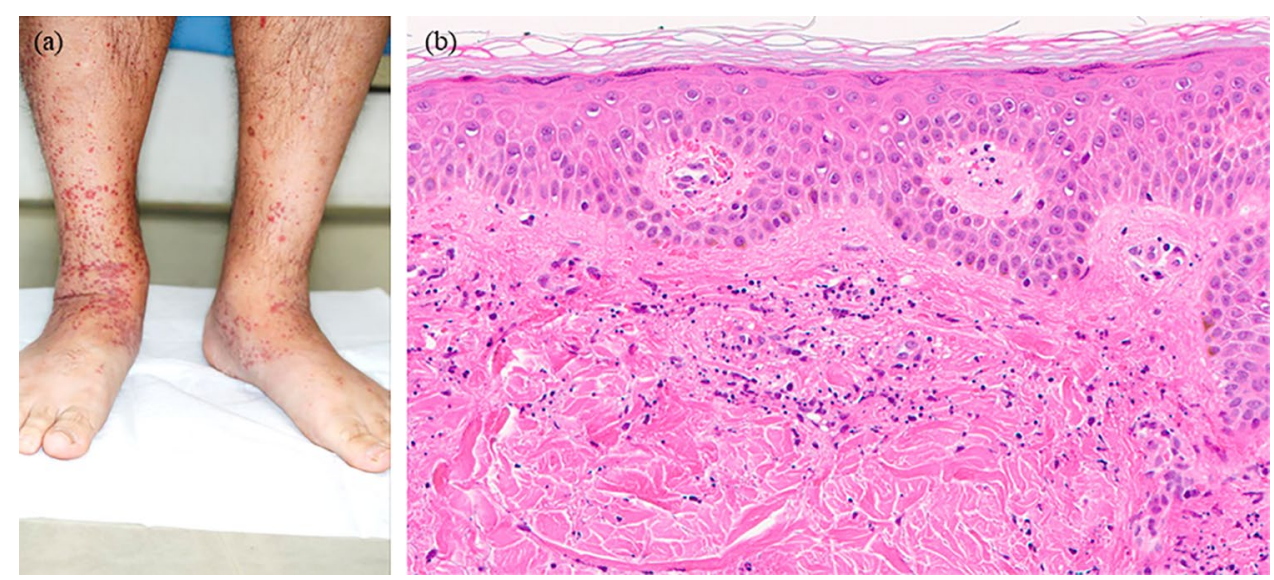
Table 1 Clinical and laboratory examination findings at time of admission

\begin{tabular}{|c|c|}
\hline Age (years) & 47 \\
\hline Body mass index $\left(\mathrm{kg} / \mathrm{m}^{2}\right)$ & 27.7 \\
\hline Blood pressure (mmHg) & $118 / 78$ \\
\hline Pulse rate (bpm) & 78 \\
\hline \multicolumn{2}{|l|}{ Features of IgA vasculitis } \\
\hline Gastrointestinal symptoms & - \\
\hline Arthritis/arthralgia & - \\
\hline Edema & - \\
\hline Palpable purpura & - \\
\hline \multicolumn{2}{|l|}{ Serology } \\
\hline Hemoglobin (g/dL) & 14.4 \\
\hline Total protein(g/dL) & 6.6 \\
\hline Albumin (g/dL) & 3.5 \\
\hline Blood urea nitrogen $(\mathrm{mg} / \mathrm{dL})$ & 12 \\
\hline Creatinine $(\mathrm{mg} / \mathrm{dL})$ & 1.24 \\
\hline eGFR (mL/min/1.73 m²) & 50.8 \\
\hline $\operatorname{IgG}(\mathrm{mg} / \mathrm{dL})$ & 1070 \\
\hline $\operatorname{IgA}(\mathrm{mg} / \mathrm{dL})$ & 349 \\
\hline $\operatorname{IgM}(\mathrm{mg} / \mathrm{dL})$ & 77 \\
\hline CH50 (U/mL) & $60<$ \\
\hline $\mathrm{C} 3(\mathrm{mg} / \mathrm{dL})$ & 110 \\
\hline $\mathrm{C} 4(\mathrm{mg} / \mathrm{dL})$ & 28.6 \\
\hline ANA & $<40$ \\
\hline MPO-ANCA (EU) & $<0.5$ \\
\hline PR3-ANCA (EU) & $<0.5$ \\
\hline Cryoglobulin & Negative \\
\hline \multicolumn{2}{|l|}{ Urinalysis } \\
\hline $\mathrm{pH}$ & 5.5 \\
\hline Blood & $3+$ \\
\hline Protein & $3+$ \\
\hline Red blood cells (hpf) & $50-99$ \\
\hline White blood cells (hpf) & $1-4$ \\
\hline Urinary protein (g/g creatinine) & 2.98 \\
\hline
\end{tabular}

ANA, antinuclear antibody; bpm, beats per minute; BUN, blood urea nitrogen; e-GFR, estimated glomerular filtration rate; hpf, high power field; MPO-ANCA, myeloperoxidase-anti-neutrophil cytoplasmic antibodies; PR3-ANCA, proteinase3-anti-neutrophil cytoplasmic antibody

medical checkup, at which time urinalysis showed no proteinuria and only mild occult blood $(1+)$. Serum creatinine was $0.89 \mathrm{mg} / \mathrm{dL}$ and estimated glomerular filtration rate (eGFR) $73.3 \mathrm{~mL} / \mathrm{min} / 1.73 \mathrm{~m}^{2}$ at that last medical checkup before the first vaccination, while at the time of admission to the Department of Nephology those were $1.24 \mathrm{mg} / \mathrm{dL}$ and $50.8 \mathrm{~mL} / \mathrm{min} / 1.73 \mathrm{~m}^{2}$, respectively. Erythrocyte sedimentation rate, $\mathrm{C}$-reactive protein, complement $\mathrm{C} 3$ and $\mathrm{C} 4$, and immunoglobulins $\mathrm{G}, \mathrm{A}$, and $\mathrm{M}$ were normal. Additional serological work-up findings for glomerulonephritis were negative, including hepatitis $\mathrm{B}$ and $\mathrm{C}$, and antinuclear and antineutrophil cytoplasmic antibodies. Determination of COVID-19 infection with an RT-PCR examination of saliva, performed as part of the general hospital admission process, showed a negative result.

A kidney biopsy was performed on day 29 after the second vaccination and demonstrated severe crescentic glomerulonephritis. Light microscopy revealed nine glomeruli with mild mesangial expansion, hypercellularity, and endocapillary hypercellularity (Fig. 2a), while cellular and fibrocellular crescent were present in three and one, respectively, of a total of 15 glomeruli examined (Fig. 2b). Hemispherical deposits, a characteristic of IgA nephropathy [20], were not observed, and no vasculitis was present in the renal vessel walls. The interstitial component was focally, mainly infiltrated by lymphocytes accompanied by mild fibrosis. Tubular atrophy was presented around the sclerotic glomeruli. Immunofluorescence showed diffuse granular mesangial staining $(3+)$ for IgA (Fig. 2c). Staining was weakly positive for $\mathrm{C} 3$, and negative for IgG as well as other immunoglobulins and complement antibodies. Histopathological features were consistent with IgA vasculitis with an ISKDC classification of IIIb. Although arthralgia, abdominal pain, and IgA deposition within small vessel walls were not observed in the skin biopsy specimen, the EULAR/PRINTO/PRES criteria of IgA vasculitis [21] were fulfilled, as the patient demonstrated palpable purpura, the mandatory criterion, as well as two supporting criteria for kidney involvement in the form of hematuria and histopathological proliferative glomerulonephritis with IgA deposits in the kidney biopsy specimen. Intravenous methylprednisolone at $1000 \mathrm{mg}$ for 3 days was initiated, after which oral prednisolone $(0.6 \mathrm{mg} /$ $\mathrm{kg} / \mathrm{day}$ ) was given. Over the following 2 -week period, kidney function improved to show a serum creatinine level of $1.06 \mathrm{mg} / \mathrm{dL}$ and proteinuria decreased to $0.36 \mathrm{~g} / \mathrm{g} \mathrm{Cr}$, though occult blood persisted.

\section{Discussion}

To the best of our knowledge, this is the first case of kidney biopsy-proven new-onset IgA vasculitis with crescentic glomerulonephritis that developed soon after receiving the mRNA-1273 COVID-19 vaccine. In the mRNA-1273 COVID-19 vaccine trial with 30,420 volunteers, macropurpuric eruption was seen in two in the placebo group and 11 in the vaccine group, while there were no cases of glomerulonephritis [22]. In other studies, two cases (33-yearold male, 40-year-old female) of new-onset IgA vasculitis without kidney involvement after receiving the BNT162b2 mRNA COVID-19 vaccine [18, 19] and one (67-year-old male) of new-onset IgA vasculitis after receiving the RNA1273 COVID-19 vaccine [13] have been reported In that latter report, the patient showed acute kidney injury and 

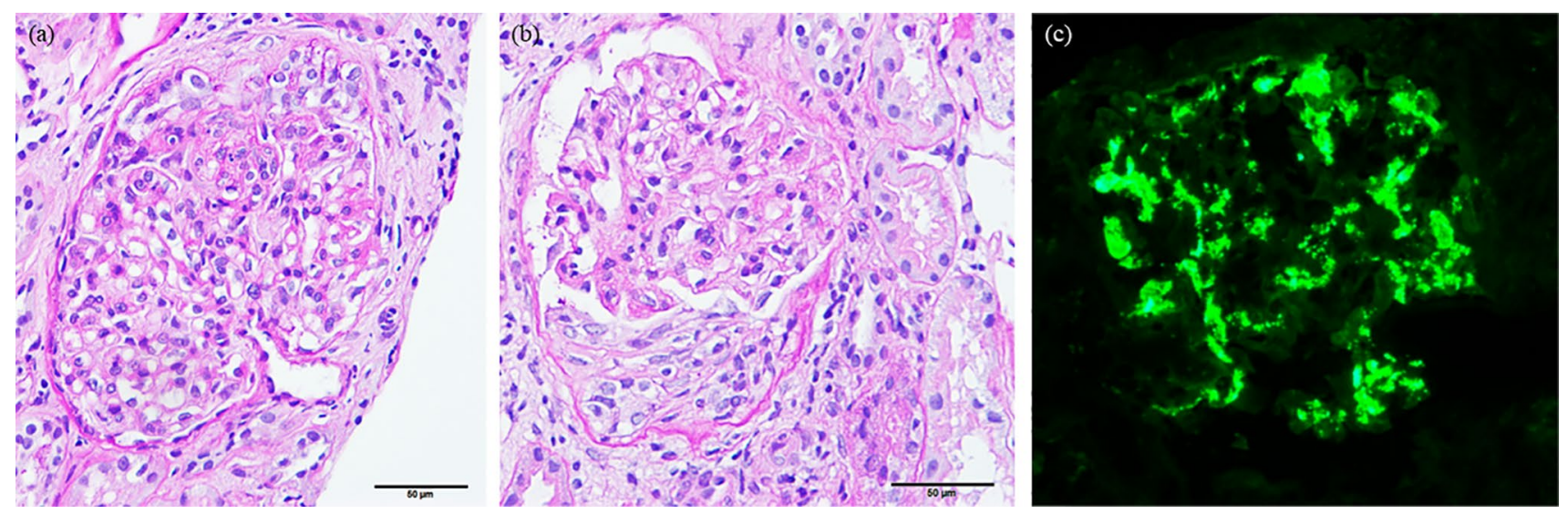

Fig. 2 Kidney biopsy findings. a Mesangial and endocapillary hypercellularity shown by light microscopy [periodic acid-Schiff, $\times 400$ ]. b Cellular crescents shown by light microscopy [periodic acid-

was treated with a 1-week course of prednisolone at $40 \mathrm{mg}$ per day, after which rash, kidney function, and urinalysis findings rapidly improved, though a kidney biopsy was not performed. In the present case, while the skin biopsy results seemed to show leukocytoclastic vasculitis, no fibrin deposition was seen and there were no $\operatorname{IgA}$ deposits within small vessel walls observed by direct immunofluorescence. In addition, urinalysis suggested glomerulonephritis. Thus, a kidney biopsy was performed. As expected, the histopathological findings showed proliferative and crescentic glomerulonephritis with IgA deposits. Although the causal relationship between administration of the mRNA-1273 COVID-19 vaccine and onset of IgA vasculitis in this case is uncertain, urinary abnormalities and kidney function deterioration were developed, soon after its vaccination. Following administration of intravenous methylprednisolone and subsequent oral prednisolone therapy, both kidney function and urinary protein were improved.

Several reports of IgA vasculitis following COVID-19 infection have been presented [23-25]. Furthermore, another report by Sugino et al. showed a summary of the characteristics of seven patients with IgA vasculitis following COVID-19 infection, including median age of 23.3 years and a 4:3 ratio of adults to children [26]. In addition to cutaneous purpura, abdominal pain and nephritis were observed in each of those seven cases, while glomerulonephritis was only seen in the adult patients and not identified in the children. Several possible mechanisms related to IgA vasculitis induction by COVID-19 infection have been proposed. A mucosal infection is believed to enhance IL- 6 production, which results in aberrant glycosylation including that of IgA1, while an increase in galactose-deficient IgA1 induces immunocomplex deposits in the mesangial region, leading to glomerulonephritis [27]. In addition, bone marrow is the source of increased B lymphocytes producing IgA1 [28,
Schiff, $\times 400]$. c Immunofluorescence findings demonstrated $3+$ granular global mesangial staining for $\operatorname{IgA}[\times 600]$

29]. A COVID-19 infection induces the release of cytokines including IL-1, IL-6, and TNF, which can lead to proliferation and mutation of these IgA1-producing B cells, resulting in $\operatorname{IgA}$ vasculitis [26]. However, in the present case of $\operatorname{IgA}$ vasculitis, a COVID-19 infection was not present, based on findings of no infectious symptoms and negative results of RT-PCR testing of saliva at the time of admission.

The exact pathogenesis of $\operatorname{IgA}$ vasculitis following a COVID-19 vaccination is unknown, though it has been reported that an mRNA COVID-19 vaccine causes antibody production and release of cytokines, which inhibits replication of the SARS-CoV2 virus in patients with IgA nephropathy [30]. Those cytokines may activate IgA1-producing B cells as well, leading to IgA vasculitis. Findings in a previous report of new-onset $\mathrm{IgA}$ vasculitis after receiving an mRNA-1273 COVID-19 vaccine suggest that the trigger in predisposed individuals may be an immune response to the spike protein or the mRNA of the mRNA-1273 COVID-19 vaccine [11]. Another report of a patient with IgA vasculitis flare after receiving the mRNA-1273 COVID-19 vaccine suggested a link between increase in anti-SARS-CoV-2 spike IgA and relapse of pre-existing IgA vasculitis [31]. Additional studies are needed to precisely elucidate the pathogenesis of IgA vasculitis following COVID-19 vaccination.

In conclusion, this is the first case of kidney biopsyproven IgA vasculitis with kidney involvement after receiving an mRNA-1273 COVID-19 vaccination. Although the mRNA-1273 vaccine is effective for prevention of COVID19 [22], immunologic side-effects including glomerulonephritis are a concern. Several cases of rare but serious adverse reactions have been reported as a part of post-marketing surveillance of COVID-19 vaccines. In the present case, soon after receiving the mRNA-1273 COVID-19 vaccine, urinary abnormalities and kidney function deterioration were developed. Physicians should be aware of 
glomerulonephritis including $\operatorname{Ig} \mathrm{A}$ vasculitis in patients who have recently undergone administration of an mRNA based COVID-19 vaccine. Should palpable purpura appear following the initial injection, careful follow-up after the second course will be necessary or use of another type of vaccination may be needed to prevent new-onset glomerulonephritis.

\section{Declarations}

Conflict of interest The authors have declared that no conflict of interest exists.

Ethical statement This article does not contain any studies with human participants or animals performed by any of the authors.

Informed consent Written informed consent was obtained from the patient for the publication of his clinical data.

\section{References}

1. Lebedev L, Sapojnikov M, Wechsler A, Varadi-Levi R, Zamir D, Tobar A, et al. Minimal change disease following the Pfizer-BioNTech COVID-19 vaccine. Am J Kidney Dis. 2021;78(1):142-5.

2. D'Agati VD, Kudose S, Bomback AS, Adamidis A, Tartini A. Minimal change disease and acute kidney injury following the PfizerBioNTech COVID-19 vaccine. Kidney Int. 2021;100(2):461-3.

3. Weijers J, Alvarez C, Hermans MMH. Post-vaccinal minimal change disease. Kidney Int. 2021;100(2):459-61.

4. Maas RJ, Gianotten S, van der Meijden WAG. An additional case of minimal change disease following the Pfizer-BioNTech COVID-19 Vaccine. Am J Kidney Dis. 2021;78(2):312.

5. Salem F, Rein JL, Yu SM, Abramson M, Cravedi P, Chung M. Report of three cases of minimal change disease following the second dose of mRNA SARS-CoV-2 COVID-19 vaccine. Kidney Int Rep. 2021;6(9):2523-4.

6. Shakoor MT, Birkenbach MP, Lynch M. ANCA-associated vasculitis following Pfizer-BioNTech COVID-19 vaccine. Am J Kidney Dis. 2021;78(4):611-3.

7. Dube GK, Benvenuto LJ, Batal I. ANCA-associated Glomerulonephritis Following the Pfizer-BioNTech COVID-19 vaccine. Kidney Int Rep. 2021 online ahead of print.

8. Tan HZ, Tan RY, Choo JCJ, Lim CC, Tan CS, Loh AHL, et al. Is COVID-19 vaccination unmasking glomerulonephritis? Kidney Int. 2021;100(2):469-71.

9. Holzworth A, Couchot P, Cruz-Knight W, Brucculeri M. Minimal change disease following the Moderna mRNA-1273 SARS-CoV-2 vaccine. Kidney Int. 2021;100(2):463-4.

10. Sekar A, Campbell R, Tabbara J, Rastogi P. ANCA glomerulonephritis after the Moderna COVID-19 vaccination. Kidney Int. 2021;100(2):473-4.

11. Anderegg MA, Liu M, Saganas C, Montani M, Vogt B, Huynh-Do $\mathrm{U}$, et al. De novo vasculitis after mRNA-1273 (Moderna) vaccination. Kidney Int. 2021;100(2):474-6.

12. Abramson M, Mon-Wei YuS, Campbell KN, Chung M, Salem F. IgA nephropathy after SARS-CoV-2 vaccination. Kidney Med. 2021;3(5):860-3.

13. Park K, Miyake S, Tai C, Tseng M, Andeen NK, Kung VL. Letter regarding: "A case of gross Hematuria and $\operatorname{IgA}$ nephropathy flare-up following SARS-CoV-2 vaccination." Kidney Int Rep. 2021;6(8):2246-7.
14. Jennette JC, Falk RJ, Bacon PA, Basu N, Cid MC, Ferrario F, et al. 2012 revised International chapel hill consensus conference nomenclature of vasculitides. Arthritis Rheum. 2013;65(1):1-11.

15. Jelusic M, Sestan M, Cimaz R, Ozen S. Different histological classifications for Henoch-Schonlein purpura nephritis: which one should be used? Pediatr Rheumatol Online J. 2019;17(1):10.

16. McNally A, McGregor D, Searle M, Irvine J, Cross N. HenochSchonlein purpura in a renal transplant recipient with prior IgA nephropathy following influenza vaccination. Clin Kidney J. 2013;6(3):313-5.

17. Jariwala S, Vernon N, Shliozberg J. Henoch-Schonlein purpura after hepatitis A vaccination. Ann Allergy Asthma Immunol. 2011;107(2):180-1.

18. Bostan E, Gulseren D, Gokoz O. New-onset leukocytoclastic vasculitis after COVID-19 vaccine. Int J Dermatol. 2021;60(10):1305-6.

19. Hines AM, Murphy N, Mullin C, Barillas J, Barrientos JC. HenochSchonlein purpura presenting post COVID-19 vaccination. Vaccine. 2021;39(33):4571-2.

20. Taguchi T, von Bassewitz DB, Grundmann E, Takebayashi S. Ultrastructural changes of glomerular basement membrane in IgA nephritis: relationship to hematuria. Ultrastruct Pathol. 1988;12(1):17-26.

21. Ozen S, Pistorio A, Iusan SM, Bakkaloglu A, Herlin T, Brik R, et al. EULAR/PRINTO/PRES criteria for Henoch-Schonlein purpura, childhood polyarteritis nodosa, childhood Wegener granulomatosis and childhood Takayasu arteritis: Ankara 2008. Part II: Final classification criteria. Ann Rheum Dis. 2010;69(5):798-806.

22. Baden LR, El Sahly HM, Essink B, Kotloff K, Frey S, Novak R, et al. Efficacy and safety of the mRNA-1273 SARS-CoV-2 Vaccine. N Engl J Med. 2021;384(5):403-16.

23. Suso AS, Mon C, Onate Alonso I, Galindo Romo K, Juarez $\mathrm{RC}$, Ramirez CL, et al. IgA vasculitis with nephritis [HenochSchonlein Purpura] in a COVID-19 patient. Kidney Int Rep. 2020;5(11):2074-8.

24. Li NL, Papini AB, Shao T, Girard L. Immunoglobulin-A vasculitis with renal involvement in a patient with COVID-19: a case report and review of acute kidney injury related to SARS-CoV-2. Can J Kidney Health Dis. 2021;8:2054358121991684.

25. Sandhu S, Chand S, Bhatnagar A, Dabas R, Bhat S, Kumar H, et al. Possible association between IgA vasculitis and COVID-19. Dermatol Ther. 2021;34(1):e14551.

26. Sugino H, Sawada Y, Nakamura M. IgA vasculitis: etiology, treatment, biomarkers and epigenetic changes. Int J Mol Sci. 2021;22(14):7538.

27. Heineke MH, Ballering AV, Jamin A, Ben Mkaddem S, Monteiro $\mathrm{RC}$, Van Egmond M. New insights in the pathogenesis of immunoglobulin A vasculitis [Henoch-Schonlein purpura]. Autoimmun Rev. 2017;16(12):1246-53.

28. Syrjanen J, Hurme M, Lehtimaki T, Mustonen J, Pasternack A. Polymorphism of the cytokine genes and $\operatorname{IgA}$ nephropathy. Kidney Int. 2002;61(3):1079-85.

29. van den Wall Bake AW, Daha MR, Haaijman JJ, Radl J, van der Ark A, van Es LA. Elevated production of polymeric and monomeric $\operatorname{IgA} 1$ by the bone marrow in IgA nephropathy. Kidney Int. 1989;35(6):1400-4.

30. Kudose S, Friedmann P, Albajrami O, D’Agati VD. Histologic correlates of gross hematuria following Moderna COVID-19 vaccine in patients with IgA nephropathy. Kidney Int. 2021;100(2):468-9.

31. Obeid M, Fenwick C, Pantaleo G. Reactivation of IgA vasculitis after COVID-19 vaccination. Lancet Rheumatol. 2021;3(9):e617.

Publisher's Note Springer Nature remains neutral with regard to jurisdictional claims in published maps and institutional affiliations. 